\title{
COMMENTARY
}

\section{Take care when taking care of fever after aneurysmal subarachnoid hemorrhage}

\author{
Stefan Wolf* \\ See related research by Schiefecker et al., http://ccforum.com/content/17/3/R88
}

\begin{abstract}
Fever is prevalent in the majority of patients after aneurysmal subarachnoid hemorrhage and is associated with worse outcome. Treatment of fever is highly recommended, but with low-grade evidence in current guidelines. The analysis by Schiefecker and colleagues reveals that the situation may be more complicated than at first glance and careless treatment may introduce further harm. The importance of this study lies in analyzing real-world multimodal neuromonitoring data, showing a pitfall in incautiously applied treatment paradigms.
\end{abstract}

\section{The fever treatment paradigm}

Even in current times of standardized operating procedures and evidence-based medicine, every ICU has its little secrets and recipes. These recipes include the method of starting enteral nutrition and how to achieve appropriate bowel movements, as well as the prevention and treatment of fever. All these factors are considered important and eventually affect final patient outcome, but there are no good data on different methods of achievement.

The paper by Schiefecker and colleagues deals with one such topic: the treatment of fever after aneurysmal subarachnoid hemorrhage (SAH) [1]. Fever in these patients is consistently linked with worsened outcome and increased mortality [2]. Current guidelines suggest aggressive treatment and active temperature management, with a low-to-moderate grade of evidence but high recommendation by expert opinion $[3,4]$. Whether lowering the fever burden is warranted in all instances or unrecognized side effects may counteract its benefit is so far unknown. Perhaps only fever prevention, but not its treatment, is

*Correspondence: stefan.wolf@charite.de

Department of Neurosurgery, Charité Berlin, Campus Virchow, Augustenburger Platz 1, 13353 Berlin, Germany warranted. A similar situation would be anemia after aneurysmal SAH, where both its occurrence and subsequent transfusion are independently linked to worse outcome and require further investigation [5].

One way of lowering the fever burden in the neurological ICU is using a continuous infusion of diclofenac, repeatedly proposed by an Italian group and supported by a small randomized trial [6]. Schiefecker and colleagues used the very same drug, but applied it as a short-time infusion lasting 30 minutes. They observed good fever control, but also a decrease in blood pressure in most patients. This decrease in blood pressure led to a decline in brain tissue oxygenation $\left(\mathrm{p}_{\mathrm{b}} \mathrm{tO}_{2}\right)$, in the majority of events below the hypoxemia threshold of $20 \mathrm{mmHg}$. Low $\mathrm{p}_{\mathrm{b}} \mathrm{tO}_{2}$, however, was linked to worse outcome.

\section{Analyzing treatment data}

The statistician Rand Wilcox once noted 'How many discoveries have been lost by ignoring modern statistical methods?' [7]. Although he dealt with robust regression on this occasion, the same could be said for the rare application of contemporary multivariate techniques in the medical community. Schiefecker and colleagues use generalized estimating equations, a statistical modeling technique for time series data, to reveal the relationship between fever treatment, blood pressure, $\mathrm{p}_{\mathrm{b}} \mathrm{tO}_{2}$ and final outcome of the patients. Time series data are messy and difficult to analyze, due to high rates of artifacts, various confounders and myriads of possible interactions.

Most of our knowledge on outcome after SAH is based on single indicators, which are either present or absent. The list includes premorbid risk factors such as hypertension or smoking habits, the severity of the initial hemorrhage, the occurrence of delayed cerebral ischemia or medical complications $[8,9]$. Data on modifiable treatment options, with the exception of the clipping versus coiling issue, are rare.

The results of the current analysis are very intriguing, presenting one of the few instances of analysis of realworld physiologic data, amenable for targeted change. We learn that treatment of fever after aneurysmal SAH does not invariantly lead to low blood pressure, and if the 
latter is preserved the decline in $\mathrm{p}_{\mathrm{b}} \mathrm{tO}_{2}$ may be prevented. It is beyond the current analysis, however, to answer the question of whether - careful - treatment of fever is better than doing nothing: for this, the number of patients is too small and controls without intervention are lacking. The authors of the paper are conservative in their conclusions and recommend tight monitoring and awareness when treating fever with parenteral diclofenac in poor-grade SAH patients [1]. I would like to add that a careful look at other treatment modalities and their side effects on blood pressure and $\mathrm{p}_{\mathrm{b}} \mathrm{tO}_{2}$ may not hurt.

\section{Let us use multimodal neuromonitoring!}

Studies like that of Schiefecker and colleagues are a plea for the use of multimodal neuromonitoring and electronic data recording: to learn more about what is actually happening in the patients we are taking care of. Without contemporary medical, statistical and data analysis technology, the insights Schiefecker and colleagues provide would not have been possible. Further use could be to validate or disprove other treatment concepts or monitoring tools - by the way, transcranial Doppler, how are you doing ... today, after more than three decades of research and use? Still no relationship with outcome [9]? The neurosurgical ICU is a technology-savvy environment with a multitude of advanced tools, providing lots of yet-to-be revealed information [10]. How to analyze such data is a challenge on its own. Having a $\mathrm{p}_{\mathrm{b}} \mathrm{tO}_{2}$ monitor sitting at the bedside is one thing, but a further, necessary, step is online data acquisition of all relevant signals, including $\mathrm{p}_{\mathrm{b}} \mathrm{tO}_{2}$, blood pressure, intracranial pressure, and so forth, together, on one screen, for online care and offline review. There are several options for doing this, from freeware to dedicated, specialized systems for recording and analysis. However, even highpriced software is a one-time expense; a low cost compared with the reimbursement for a single case of severe $\mathrm{SAH}$, as well as the burden on society for one patient with a less than optimal treatment outcome.

Therefore, let us use multimodal neuromonitoring appropriately, and learn from it. This is the base for future intelligent, event-driven and monitoring-driven studies trying to improve the final outcome of our patients.
Abbreviations

$\mathrm{p}_{\mathrm{b}} \mathrm{tO}_{2}$, brain tissue oxygenation; $\mathrm{SAH}$, subarachnoid hemorrhage.

\section{Competing interests}

The author has received lecture honoraria from Integra Neurosciences, France.

Published: 1 July 2013

\section{References}

1. Schiefecker AJ, Pfausler B, Beer R, Sohm F, Sabo J, Knauseder V, Fischer M, Dietmann A, Hackl WO, Thomé C, Schmutzhard E, Helbok R: Parenteral diclofenac infusion significantly decreases brain-tissue oxygen tension in patients with poor-grade aneurysmal subarachnoid hemorrhage. Crit Care 2013, 17:R88.

2. Scaravilli V, Tinchero G, Citerio G: Fever management in SAH. Neurocrit Care 2011, 15:287-294.

3. Diringer MN, Bleck TP, Claude Hemphill J 3rd, Menon D, Shutter L, Vespa P, Bruder N, Connolly ES Jr, Citerio G, Gress D, Hänggi D, Hoh BL, Lanzino G, Le Roux P, Rabinstein A, Schmutzhard E, Stocchetti N, Suarez Jl, Treggiari M, Tseng MY, Vergouwen MD, Wolf S, Zipfel G; Neurocritical Care Society: Critical care management of patients following aneurysmal subarachnoid hemorrhage: recommendations from the Neurocritical Care Society's Multidisciplinary Consensus Conference. Neurocrit Care 2011, 15:211-240.

4. Connolly ES Jr, Rabinstein AA, Carhuapoma JR, Derdeyn CP, Dion J, Higashida RT, Hoh BL, Kirkness CJ, Naidech AM, Ogilvy CS, Patel AB, Thompson BG, Vespa P; American Heart Association Stroke Council; Council on Cardiovascular Radiology and Intervention; Council on Cardiovascular Nursing; Council on Cardiovascular Surgery and Anesthesia; Council on Clinical Cardiology: Guidelines for the management of aneurysmal subarachnoid hemorrhage: a guideline for healthcare professionals from the American Heart Association/American Stroke Association. Stroke 2012 43:1711-1737.

5. Le Roux PD: Anemia and transfusion after subarachnoid hemorrhage. Neurocrit Care 2011, 15:342-353.

6. Cormio M, Citerio G: Continuous low dose diclofenac sodium infusion to control fever in neurosurgical critical care. Neurocrit Care 2007, 6:82-89.

7. Wilcox RR: How many discoveries have been lost by ignoring modern statistical methods? Am Psychol 1998, 53:300-314.

8. Wartenberg KE, Schmidt JM, Claassen J, Temes RE, Frontera JA, Ostapkovich N, Parra A, Connolly ES, Mayer SA: Impact of medical complications on outcome after subarachnoid hemorrhage. Crit Care Med 2006, 34:617-623; quiz 624.

9. Frontera JA, Fernandez A, Schmidt JM, Claassen J, Wartenberg KE, Badjatia N, Connolly ES, Mayer SA: Defining vasospasm after subarachnoid hemorrhage: what is the most clinically relevant definition? Stroke 2009, 40:1963-1968.

10. Hemphill JC, Andrews P, De Georgia M: Multimodal monitoring and neurocritical care bioinformatics. Nat Rev Neurol 2011, 7:451-460.

doi:10.1186/cc12768

Cite this article as: Wolf S: Take care when taking care of fever after

aneurysmal subarachnoid hemorrhage. Critical Care 2013, 17:160. 